\title{
Atlas Ecuador y sus provincias, Edición Braille
}

Cuesta, Rosa y Villagómez, Martha, Instituto Geográfico Militar, Quito, 2015, 30 pp. Certificado de propiedad intelectual No. QUI-047614.

\section{Xavier Molina S. Universidad de Fuerzas Armadas ESPE, Ecuador}

En la actualidad, la idea de una sociedad del conocimiento se fundamenta básicamente en la necesidad de información que se requiere en todos los ámbitos de manera cotidiana, a esta idea se debe sumar la necesidad de inclusión de personas con capacidades especiales que demandan tener acceso a información de calidad, utilizando nuevas formas de aprendizaje y ajustadas a las necesidades de este grupo poblacional, con el fin de impulsar el desarrollo de capacidades cognoscitivas que les permita incorporarse de manera activa en la sociedad.

Sustentado en el planteamiento anterior, el Instituto Geográfico Militar del Ecuador, en el año 2015, edita por primera vez el Atlas Ecuador y sus provincias, en su edición en Braille, como una iniciativa dentro de la misión permanente de crear mapas geográficos. Este nuevo producto ha sido elaborado a partir de una mirada inclusiva, logrando sumar más actores en el ámbito del conocimiento geográfico del país.

El Atlas está dirigido a personas con diferente deficiencia visual, esta versión en Braille presenta, mediante símbolos los límites políticos administrativos a nivel provincial, utilizando como mecanismo de lectura una secuencia de puntos, con el objetivo de ser percibidos a través del tacto por las personas con discapacidad visual, de esta manera se generó cartografía táctil a la que se sumó dos tipos de recursos gráficos para complementar su representación, estos son:

1. Con color y texto y,

2. En relieve (alfabeto Braille)

El uso de recursos de diseño cartográfico acorde a las normas cartográficas actuales y en función de la población objetivo, permite que la lectura de este documento alcance a un mayor número de personas con discapacidad visual. Para la elaboración del Atlas, que se compone por un total de 30 hojas, se utilizó información 
del mapa oficial del Ecuador a escala 1:1000 000; la impresión en texto y color se realizó en las instalaciones de la Gestión de Seguridad Documentaria del Instituto Geográfico Militar y, finalmente la impresión en Braille fue ejecutada por la imprenta de la Federación de Ciegos del Ecuador, localizada en la ciudad de Riobamba, provincia de Chimborazo.

En referencia al contenido del Atlas, se presenta una hoja inicial donde se registra información relevante del Ecuador en términos generales como: población, superficie, fechas importantes, entre otras; seguidamente se muestra el mapa político de todo el territorio ecuatoriano en sus ambientes insular y continental, y finalmente se exponen cada una de las 24 provincias identificando las provincias colindantes, así como los datos más representativos de cada una de ellas.

Es notorio que la edición del Atlas está alineada con lo dispuesto en la Constitución de la República del Ecuador, donde se estipula el derecho de todo ciudadano al acceso a información de calidad. Uno de los logros más importantes fue el trabajo colaborativo y articulado entre diferentes instituciones del Estado, las cuales aportaron desde el ámbito de sus competencias y conocimientos, configurando de esta manera un producto de calidad, puesto al alcance de la comunidad con discapacidad visual en el país. Esta publicación, en el año 2019, fue galardonada con un reconocimiento por parte de la Corporación Líderes para Gobernar y fue considerada como una práctica ejemplar en el ámbito de la educación inclusiva, destacando así el esfuerzo realizado por una entidad pública en apoyo al desarrollo del Ecuador.

Para concluir, deseo resaltar que este proyecto es factible de ser replicado en productos similares para la educación en cualquier disciplina y dirigidos a grupos poblacionales vulnerables de la sociedad ecuatoriana. 